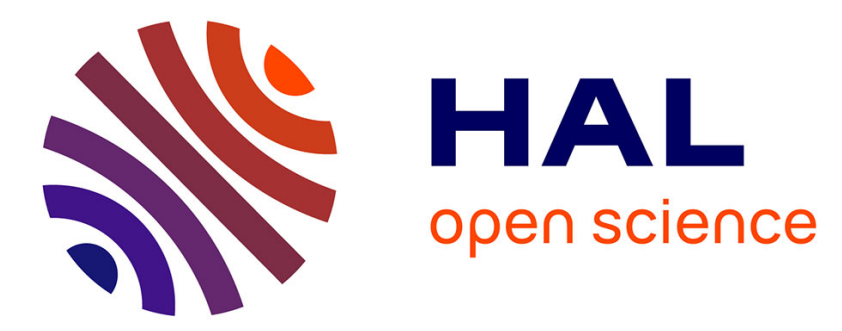

\title{
NADPH oxidase activity is associated with cardiac osteopontin and pro-collagen type I expression in uremia.
}

Aurélie Goux, Christine Feillet-Coudray, Bernard Jover, Gilles Fouret, Anne-Sophie Bargnoux, Cécile Cassan, Sylvain Richard, Stéphanie Badiou, Jean-Paul Cristol

\section{To cite this version:}

Aurélie Goux, Christine Feillet-Coudray, Bernard Jover, Gilles Fouret, Anne-Sophie Bargnoux, et al.. NADPH oxidase activity is associated with cardiac osteopontin and pro-collagen type I expression in uremia.. Free Radical Research, 2011, 45 (4), pp.454-460. 10.3109/10715762.2010.541455 . hal00593599

\section{HAL Id: hal-00593599 https://hal.science/hal-00593599}

Submitted on 26 Sep 2017

HAL is a multi-disciplinary open access archive for the deposit and dissemination of scientific research documents, whether they are published or not. The documents may come from teaching and research institutions in France or abroad, or from public or private research centers.
L'archive ouverte pluridisciplinaire HAL, est destinée au dépôt et à la diffusion de documents scientifiques de niveau recherche, publiés ou non, émanant des établissements d'enseignement et de recherche français ou étrangers, des laboratoires publics ou privés. 


\title{
TITLE
}

\section{NADPH oxidase activity is associated with cardiac osteopontin and pro-collagen type I expression in uremia.}

\section{RUNNING HEAD}

\section{NADPH oxidase and cardiac protein modifications in uremia.}

\author{
Authors \\ Aurélie Goux ${ }^{1}$, Christine Feillet-Coudray ${ }^{2}$, Bernard Jover ${ }^{3}$, Gilles Fouret ${ }^{4}$, Anne-Sophie
} Bargnoux ${ }^{1,5}$, Cécile Cassan ${ }^{4}$, Sylvain Richard ${ }^{4}$, Stéphanie Badiou ${ }^{1,5}$, Jean-Paul Cristol ${ }^{1,5}$.

\section{Addresses}

${ }^{1}$ UMR 204 - Prévention des Malnutritions et des Pathologies Associées, IRD, University Montpellier 1 et 2, Montpellier, France

${ }^{2}$ EA 3127 - Groupe Rein et Hypertension, Université Montpellier 1, Montpellier, France

${ }^{3}$ INRA, UMR 866 - Unité de différentiation cellulaire et croissance, Montpellier, France

${ }^{4}$ INSERM U637, CHU Arnaud de Villeneuve Physiopathologie Cardiovasculaire, Montpellier, France

${ }^{5}$ Laboratoire de Biochimie, Hôpital Lapeyronie, Montpellier, France

Correspondence: Jean-Paul Cristol, Laboratoire de Biochimie, CHU Lapeyronie, 371 Avenue du Doyen Gaston Giraud, 34295 Montpellier cedex 5, France. Phone: +33 467338314. Fax: +33 467338393. Email: jp-cristol@chu-montpellier.fr

\begin{abstract}
Cardiovascular disease is a frequent complication inducing mortality in chronic kidney disease (CKD) patients, which can be determined by both traditional risk factors and nontraditional risk factors such as malnutrition and oxidative stress. We aimed to investigate the role of oxidative stress in uremia-induced cardiopathy in an experimental CKD model. CKD was induced in Sprague-Dawley rats by a four week diet supplemented in adenine, calcium and phosphorus and depleted in proteins. CKD was associated with a three-fold increase in superoxide anion production from the NADPH oxidase in the left ventricle, but the maximal activity of mitochondrial respiratory chain complexes was not different. Although manganese mitochondrial SOD activity decreased, total SOD activity was not affected and catalase or GPx activities were increased, strengthening the major role of NADPH oxidase in superoxide anion output. Superoxide anion output wass associated with enhanced expression of osteopontin (x 7.7) and accumulation of pro-collagen type I (x 3.7). To conclude, the increased activity of NADPH oxidase during CKD was associated with protein modifications which could initiate a pathway leading to cardiac remodeling.
\end{abstract}

Keywords: End stage renal failure, adenine diet, oxidative stress, NADPH oxidase. 


\section{Introduction}

The incidence of chronic kidney disease (CKD) increases constantly in the general population, with a prevalence of about $10 \%$ in Europe [1]. The high rate of cardiovascular (CV) complications observed in hemodialysis patients is only partly explained by traditional risk factors, such as aging, gender, hypertension, diabetes, smoking, dyslipidemia and obesity. Indeed, non-traditional risk factors including malnutrition, inflammation and oxidative stress have emerged $[2,3]$. Protein-energy malnutrition is a common feature during hemodialysis, related in part to the uremic syndrome per se (physical inactivity, controlled diet, anorexia, psychosocial factors) and for a second part to the inflammation and oxidative stress (increased catabolism, increased resting energy expenditure, anorexia) [4,5]. Malnutrition, oxidative stress and inflammation are closely interconnected [2,3] as inflammation and malnutrition induce superoxide anion production through the nicotinamide adenine dinucleotide phosphate (NADPH) oxidase system and decrease the antioxidant capacities (vitamins E, C, carotenoides) $[3,6]$.

Uremic cardiomyopathy is characterized principally by left ventricle (LV) dysfunction, present in 50 to $60 \%$ of patients and by LV hypertrophy (up to $74 \%$ of patients beginning hemodialysis) [7]. Interstitial fibrosis is a constant finding in heart biopsies and could be partly responsible for ventricular arrhythmias and sudden death in these patients $[7,8]$. Pathological expression of pro-collagen type I or collagen type I, a fibrillar protein of the extracellular matrix, in parallel with unchanged or depressed collagen degradation, characterizes interstitial fibrosis and finally cardiac dysfunction [8,9].

In the heart, the NADPH oxidase system and the respiratory chain complexes of the mitochondria are the two major sources of Reactive Oxygen Species (ROS) [10,11]. When moderate amounts of ROS are produced, it specifically regulates intracellular signaling pathways by reversible oxidation of proteins such as transcription factors or protein kinases [12]. However, when they are produced at high levels, mitochondrial or NADPH-derived ROS can also have deleterious effects by massive and irreversible oxidation of their principal targets (lipids, proteins and DNA). The NADPH oxidase (NOX) system is a membrane associated enzyme composed of five subunits, catalyzing the one electron reduction of oxygen, using as the electron donor NADPH or to a lesser extend NADH [10]. In the heart, the two isoforms NOX2 and NOX4 are present, and both need the regulatory subunit p22phox to be active [10,13]. To prevent ROS damages, cardiac tissue possess enzymatic antioxidant systems: superoxide dismutase (SOD) enzyme converts superoxide anion to hydrogen peroxide, and hydrogen peroxide can be rapidly removed by glutathione peroxidase (GPx) or by catalase [14]. An imbalance between oxidative stress production and defenses would result in increased cardiac oxidative stress, an event actually thought to be linked to increased risk of LV hypertrophy during CKD $[3,10]$.

This work aimed to evaluate the involvement of oxidative stress in cardiac complications induced by uremia, using an animal model of CKD associated with malnutrition. Chronic renal failure was induced by a diet supplemented in adenine, calcium and phosphorus, and depleted in proteins [15].

\section{Methods}

\section{Animals and diets}

Eight Sprague-Dawley rats (Elevage Janvier, Le Genest Saint Isle, France) aged of 13 weeks were used. Rats were housed in an air-conditioned room with a standard 12-h light/dark cycle. The rats were randomized into two groups of 4 animals: a control group (control) was fed for 4 weeks a standard diet and an experimental group (adenine) was fed for 4 weeks a semi purified low protein and high adenine, high calcium and high phosphorus diet. Diets were purchased from SAFE (Augy, France). The standard diet contains $3 \%$ fat, $17 \%$ proteins, 
$60 \%$ carbohydrates, $5 \%$ cellulose, $0.83 \%$ calcium and $0.59 \%$ phosphorus. The adenine diet contained $5 \%$ fat, $3 \%$ proteins, $74.6 \%$ carbohydrates, $7 \%$ cellulose, $0.8 \%$ adenine, $1.13 \%$ calcium and $0.86 \%$ phosphorus. Rats were given free access to water and food. No mortality was observed among both groups.

In physiological conditions, adenine and 5-phosphoribosyl-1-pyrophosphate are converted to AMP by adenine phosphoribosyltransferase (APRT) [16]. APRT deficiency is characterized in human by urolithiasis and kidney disease [17] and animal models with induced APRT deficiency demonstrate the same symptoms, due to the formation of 2,8dihydroxyadenine by xanthine oxidase $[16,17]$. The oxidation of adenine by xanthine oxidase leads to precipitation of crystals in the tubules of the kidney, causing a macroscopically observable tubular obstruction $[16,18]$, resulting in an increase of creatinine and urea in the serum as well as a reduction of their urinary excretion $[15,18]$.

In order to measure body growth, urinary excretion, diet and water consumption, rats were housed in metabolic cages; these four parameters were determined daily, and energy intake was calculated. Animals were followed up for tail-cuff blood pressure at day 1, 14 and 28 of experiment and for urinary parameters at day 3,14 and 28 of experiment. At the end of the 4 weeks of experiment, animals were anesthetized with isoflurane prior to echocardiography. Two days later, animals were anesthetized with sodium pentobarbital (60 $\left.\mathrm{mg} \mathrm{kg}{ }^{-1}\right)$. Blood was taken with a heparinized syringe and centrifuged at $1000 \mathrm{~g}$ for $10 \mathrm{~min}$ at $4^{\circ} \mathrm{C}$. Supernatants were collected and aliquots were frozen in liquid nitrogen, and stored at $80^{\circ} \mathrm{C}$ until analysis. At sacrifice, hearts were quickly removed and weighted. The LV were isolated, weighted, cut in different pieces and frozen in liquid nitrogen before conservation at $-80^{\circ} \mathrm{C}$. Heart weight and LV weight were determined to calculate cardiac parameters.

\section{Routine biochemical analyses}

Plasma levels of proteins, albumin, urea, creatinine, calcium and inorganic phosphate were measured by routine biochemistry on an AU 640 analyzer (Olympus, Rungis France). Corrected calcium was calculated and took into account albumin concentration ([corrected calcium $\left.]=[\text { calcium }]_{\text {plasma }}+0,02 \times(40 \text {-[albumin }]_{\text {plasma }}\right)$. Phosphocalcic product was calculated with the following formula: plasmatic phosphorus concentration multiplied by plasmatic corrected calcium concentration. Lipid parameters (total cholesterol, HDL-cholesterol, triglycerides) and urinary parameters (creatinine, inorganic phosphate) were determined by routine techniques on Architect C8000 (Abbott, Rungis, France). Protein levels in tissue homogenates were measured by the Lowry method (Protein Dc, Bio-Rad Laboratories, Marne la Coquette, France) [19].

\section{Determination of oxidative markers}

LV homogenates were prepared on ice in a ratio of $1 \mathrm{~g}$ wet tissue for $9 \mathrm{~mL}$ phosphate buffer $\left(50 \mathrm{mmol} \mathrm{L}^{-1}, \mathrm{pH} 7\right)$ using an UltraTurax homogenizer, then centrifuged at $1000 \mathrm{~g}$ for $10 \mathrm{~min}$ at $4^{\circ} \mathrm{C}$. Supernatant was collected and stored at $-80^{\circ} \mathrm{C}$ until analysis.

Lipid peroxidation levels or thiobarbituric acid-reactive substances (TBARS) were measured in plasma according to the method of Yagi [20] and in tissues homogenates according to the method of Sunderman et al. [21].

Anti-oxidative activities in LV including total and manganese superoxide dismutases (SOD and Mn-SOD) were measured according to the method of Marklund [22]. Catalase and glutathione peroxidase (GPx) activities were measured in tissues according to the methods of Beers and Sizer [23] and of Flohe and Gunzler [24] respectively. 
Determination of mitochondrial respiratory chain complex activities in tissue

LV homogenates were prepared as described above. Complex I (CI) activity was measured according to Janssen et al. [25]. Complex II (CII) and complex II+III (CII+CIII) activities were measured according to Rustin et al. [26]. Cytochrome c oxidase (COX) activity was measured according to Wharton and Tzagoloff [27] and citrate synthase (CS) activity was measured according to Srere [28].

\section{Determination of NADPH oxidase activity}

NADPH oxidase superoxide anion production was evaluated in frozen LV as previously described [11]. Briefly, the LV tissues were rinsed in Krebs buffer, homogenized using an Ultra Turrax T25 basic (Irka-Werke) in ice-cold Krebs buffer, then centrifuged at 1000g for $20 \mathrm{~min}$ at $4^{\circ} \mathrm{C}$. Supernatants were then incubated at $37^{\circ} \mathrm{C}$ for $30 \mathrm{~min}$ in the presence or absence of diphenyleiodonium (DPI, $100 \mu \mathrm{mol} \mathrm{L}^{-1}$ ), an inhibitor suppressing NADPH oxidase activity. Lucigenin (final concentration $10 \mu \mathrm{mol} \mathrm{L}^{-1}$, electron acceptor)-enhanced chemiluminescence was assessed to determine superoxide anion generation after adding excess NADPH $\left(100 \mu \mathrm{mol} \mathrm{L}{ }^{-1}\right)$, the substrate for NADPH oxidase. The chemiluminescence signals were measured by a microplate luminometer LB96V (Berthold). Results are expressed as relative light units (RLU) and are corrected for protein concentration.

\section{Immunoblotting}

Protein expressions were analyzed by immunoblotting as described previously by Sutra T. et al. [29]. Briefly, proteins were extracted from the frozen LV of four rats per group and $50 \mu \mathrm{g}$ proteins were separated with a SDS-PAGE appropriate to the size of each protein, transferred to a nitrocellulose membrane and blocked over-night at $4^{\circ} \mathrm{C}$. Then, membranes were incubated 1 hour at room temperature with primary antibody against p22-phox (1/100), OPN $(1 / 100)$, collagen type I $(1 / 200)$ or $\beta$-actin $(1: 1000$, loading reference) (Santa Cruz Biotechnology Inc., Santa Cruz, CA, USA) in blocking buffer. Blots were washed, incubated with secondary antibody (1/5000), washed again and treated with enhanced chemiluminescence detection reagents (ECL, Amersham Biosciences Europe GmbH, Orsay, France). $\beta$-actin was used as loading references, and blot intensities were measured using the BIO-Profil 1D software (FisherBioblock).

\section{Echocardiography}

Doppler-echocardiography was performed in anesthetized animals (2\% Isoflurane, Baxter) with a Vivid7Pro (GE Healthcare, USA) equipped with a $10 \mathrm{MHz}$ transducer. Rats were positioned on their left side.

A two-dimensional view of the LV was obtained at the level of the papillary muscles in a parasternal short axis view [30]. LV morphology parameters were measured from Mmode traces recorded through the anterior and posterior walls [31]. LV shortening fraction was calculated as [(LVIDd - LVIDs) / LVIDd x 100] were LVIDd and LVIDs are respectively end diastolic and end systolic LV internal dimensions. LV shortening fraction normal range is $40-50 \%$ in anesthetized rats. The relative wall thickness [32] was calculated as (AWT + PWT) / LVIDd where AWT and PWT are respectively the LV anterior and posterior wall thickness in diastole.

The cardiac outflow was calculated as HR $\mathrm{x}$ VTI $\mathrm{x} \mathrm{Ao}^{2} \mathrm{x} \pi / 4$ where HR is the heart rate, VTI is the velocity time integral of the aortic flow assessed by Doppler in a suprasternal view, and Ao is the aorta diameter measured in a long axis view [33]. The cardiac outflow was then normalized to the body weight. 


\section{Statistical analysis}

Results are expressed as means \pm SEM. Statistical analysis was based on the non parametric Mann-Whitney test. Statistical analysis was performed using the Stat View program (SAS Institute, Cary, NC). $\mathrm{p}<0.05$ was considered statistically significant.

\section{Results}

\section{Rat model of adenine induced uremia}

At sacrifice time, the adenine group exhibited increases in plasma creatinine and urea when compared to control group (table I). Furthermore, the evolution of urinary creatinine excretion during the experiment showed a significant decline (table II). In term of phosphocalcic metabolism, total and corrected plasma calcium levels were not different in the rats fed the diet containing adenine (table I). A rise in the plasma level of phosphorus was detected (table I), explaining the 3 fold increase in the phosphocalcic product $(6.9 \pm 0.4$ $\left.(\mathrm{mmol} \mathrm{L})^{-1}\right)^{2}$ for the control rats versus $19.8 \pm 2.6\left(\mathrm{mmol} \mathrm{L}^{-1}\right)^{2}$ for the adenine-fed rats, $\mathrm{p}=$ 0.02). Regarding to the phosphorus urinary excretion during the time course of the experiment, the adenine fed rats had an excretion 3.5 fold higher at the beginning of the experiment compared to the end (table II).

[Insert Table I and II about here]

\section{Nutritional parameters}

The average initial weight was $483 \pm 4 \mathrm{~g}$ for the control rats and $483 \pm 4 \mathrm{~g}$ for the adenine-fed rats. The control rats gained $8.8 \pm 1.8 \%$ of weight (final weight: $526 \pm 9 \mathrm{~g}$ ) and the adenine-fed rats significantly lost $43.7 \pm 1.5 \%$ of their initial weight (final weight: $272 \pm$ $7 \mathrm{~g}$ ). In agreement with this observation, the total cumulated energy intake during the experimental period was $2171 \pm 71 \mathrm{kcal}$ for the control rats and $862 \pm 47 \mathrm{kcal}$ for the adeninefed rats $(\mathrm{p}=0.02)$. During the 28 days of diet, the average water consumption $(31 \pm 6 \mathrm{~mL}$ vs. $28 \pm 4 \mathrm{~mL})$ and diuresis $(19 \pm 5 \mathrm{~mL}$ vs. $22 \pm 3 \mathrm{~mL})$ was not significantly different between control and adenine groups, respectively.

For the nutritional status, table I shows a significant decrease in albumin in adenine diet versus control. By contrast, adenine-fed rats exhibit an increase in total cholesterol compared to controls, which is mainly due to increased non-HDL cholesterol (table I).

\section{Oxidative stress parameters}

Plasmatic TBARS measurement demonstrates a 56\% increase in lipid oxidation associated to a non significant increase in cardiac TBARS $(p=0.15)$ (table III).

For cardiac anti-oxidative enzymes, Mn-SOD activity decreases from $30 \%$ in LV of adenine fed rats, without difference in total SOD between groups. Catalase and GPx, are increased by $75 \%$ and $38 \%$ respectively in adenine-fed rats compared to control rats (Table III).

For mitochondrial respiratory complex activities, no difference was observed among the two groups of rats for CI, CII, CII+III, COX, and CS activities (mU x mg ${ }^{-1}$ protein) in LV (table III).

In LV, a three-fold increase activity of NADPH oxidase was observed in adenine-fed

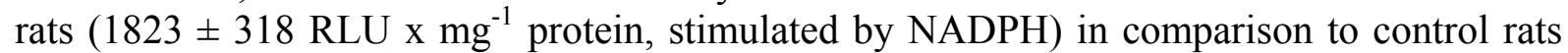
$\left(608 \pm 50 \mathrm{RLU} \mathrm{X} \mathrm{mg}^{-1}\right.$ protein) (table III). However, the expression of the regulatory subunit p22-phox from the NADPH oxidase did not change between the two conditions (figure 1-A). [Insert Table III about here] 


\section{Cardiovascular features}

Tail-cuff blood pressure. As observed in figure 2, blood pressure remained stable for more than 2 weeks. Nevertheless, after four weeks of adenine diet, the tail-cuff blood pressure was slightly elevated of approximately $30 \mathrm{~mm}$ of mercury $(\mathrm{p}=0.02)$.

[Insert Figure 2 about here]

Cardiac function. Hearts were smaller in the adenine-fed rats $(0.97 \pm 0.06 \mathrm{~g}$ versus $1.25 \pm 0.02 \mathrm{~g}$ for the control rats, $\mathrm{p}=0.02$ ). However, LV weight index (LV weight reported to the total body weight) was significantly higher $(\mathrm{p}=0.02)$ for the adenine-fed rats $(2.60 \pm$ $\left.0.18 \mathrm{mg} \mathrm{x} \mathrm{g}^{-1}\right)$ compared to the control rats $\left(1.72 \pm 0.07 \mathrm{mg} \mathrm{x} \mathrm{g}^{-1}\right)$. As observed with the echocardiography, cardiac morphology, represented by the relative wall thickness, was not different between groups $(0.345 \pm 0.013$ for the control rats versus $0.361 \pm 0.009$ for the adenine-fed rats, $\mathrm{p}=0.39$ ). Cardiac contractility (LV shortening fraction: $41.9 \pm 2.5 \%$ for the control rats versus $43.4 \pm 2.6 \%$ for the adenine-fed rats, $\mathrm{p}=0.77)$ and cardiac outflow $(0.300$ $\pm 0.024 \mathrm{~cm}^{3} \mathrm{~min}^{-1} \mathrm{x} \mathrm{g}^{-1}$ for the control rats versus $0.277 \pm 0.021 \mathrm{~cm}^{3} \mathrm{~min}^{-1} \mathrm{x} \mathrm{g}^{-1}$ for the adenine-fed rats, $p=0.48$ ) were not affected after 4 weeks of experiment.

$L V$ protein expression. As observed in figure 1-B and 1-C, OPN expression and procollagen type I expression are significantly increased in adenine-fed rats in comparison to controls from 7.7-fold and 3.7-fold respectively. Collagen type I expression (figure 1-D) is not significantly different between groups.

[Insert figure 1 about here]

\section{Discussion}

Our results, using a relevant rat model of uremia associated with malnutrition, strongly suggest that superoxide anion over-production mainly due to NADPH oxidase activity could be involved in OPN and pro-collagen type I expression.

Interestingly, this model could mimic the MIA syndrome which has emerged as a key non-traditional risk factor in end stage renal disease $[2,4,5]$. Malnutrition, demonstrated by the dramatic weight loss, decrease in caloric intake and hypoalbuminemia, was associated with uremia in the adenine-fed rats as previously reported $[15,18]$.

During the last decade, oxidative stress, which is closely related to malnutrition, has emerged as a potential determinant of cardiovascular diseases in hemodialysis patients [34]. Lipid oxidative modifications are present in plasma and to a lesser extend in LV of uremic rats, as proven by increase in TBARS. In the LV, oxidative modifications could be dependent on the NADPH oxidase, as our results clearly show a three-fold increase in NADPH oxidase superoxide anion production. By contrast, mitochondrial contribution to oxidative stress could not be retained in our model, since the maximal activities of mitochondrial respiratory chain complexes were not altered. These observations extend a previous report showing that cardiac NADPH oxidase activity is increased four-fold in nephrectomized rats, but neither mitochondria, nor cardiac functionality were estimated in this study [35]. The specificity of the NADPH oxidase system in the heart has also been determined in obesity and metabolic syndrome [11,29].

In order to counterbalance oxidative modifications, antioxidant systems act for the clearance of ROS [14,36]. Heart antioxidant systems are very effective, as the high production in superoxide anion only slightly affect oxidative markers. SOD, the superoxide anion scavenging system in LV, is not affected by uremia. However, the mitochondrial SOD (MnSOD), responsible for neutralisation of mitochondrial superoxide anion or for mitochondrial 
protection from external production of ROS [36], was decreased. As no modification of the maximal activities of mitochondrial respiratory chain complexes was observed, alteration of Mn-SOD activity probably reflects a decrease in mitochondrial protection from external production of ROS. The two other scavenging systems, namely catalase and GPx, involved in heart protection from ROS and reactive chlorine species [36], increase concomitantly to NADPH oxidase activity. Taken together, the increase NADPH oxidase activity, in association with the maintenance of global anti-oxidative enzyme system, confirms the role of NADPH oxidase in superoxide output.

Increase superoxide anion output resulting from increase NADPH oxidase activity could account for de novo OPN and pro-collagen type I expression, a signaling pathway probably involving ERK $1 / 2$ and implicated in the development of cardiac complications $[29,37]$. In addition, in mice lacking gp91phox (catalytic subunit of NOX2), stimulation with angiotensin II induces neither cardiac collagen over-expression, nor cardiac hypertrophy [38]. OPN, a non-collagenous matricellular protein regulating cell to extracellular matrix interactions, is missing from our control rats' LV in agreement with the review of Okamoto H. [37,39]. Its expression, low or absent in normal postnatal life, is concomitant with the development of heart failure and appears in response to pressure or metabolic disorders $[39,40]$. OPN is secreted by fibroblasts and cardiomyocytes among others and could be stimulated by the superoxide anion produced by NADPH oxidase [29,37]. OPN induces procollagen type I synthesis by fibroblasts, which is processed in mature fibers of collagen type I by removal of $\mathrm{N}$ and $\mathrm{C}$-terminal propeptides by Bone Morphogenetic Protein 1 (BMP-1) $[9,41]$. This extracellular matrix rearrangement is associated with extended areas of fibrosis in mice heart [9]. To support that, mice lacking OPN develop neither pro-collagen or collagen deposition, nor cardiac fibrosis [29,37,39]. In our model, processing of pro-collagen type I to collagen type I and fibrosis induction would maybe occurs in a longer term experiment. As demonstrated in the liver, an induction of OPN as early as day one of experiment, results in fibrosis after 8 weeks of experiments, with a continuous increase in pro-collagen type I from one to four weeks of experiment [42].

Finally, despite LV weight index suggests LV hypertrophy, no clear cardiac alteration (morphology, function or contractility) was observed in this experimental model at the time of echocardiographic examination. The dramatic loss of body weight was a major confounding factor in this phenomenon. However, the cardiac protein pattern expression has already been associated with LV hypertrophy in previous studies [11,29]. Hypertension, which has been previously related to increased heart NADPH oxidase activity $[43,44]$, is currently considered as a risk factor of $\mathrm{CV}$ disease and myocardial fibrosis [8]. However, the delayed increase in blood pressure, previously reported in rat model of renal failure [45], occurring between two and four weeks of experiment, leads to a short exposure to hypertension, probably not long enough to induce cardiac modifications. LV hypertrophy, fibrosis and abnormal cardiac functionality resulting from pro-fibrosis protein expression and elevated blood pressure may develop later.

This study does not exclude an effect of malnutrition in OPN and pro-collagen type I expression; it has been proved that a methionine and choline depleted diet could induce liver OPN expression and liver fibrosis [42]. However, the oxidative stress hypothesis in uremia induced cardiopathy is further supported by the efficiency of dl- $\alpha$-tocopherol to prevent cardiac fibrosis in nephrectomized rats [45]. Other treatments with enalapril or paricalcitol in nephrectomized rats were able to decrease cardiac oxidative stress but functional or morphologic effects were not assessed [35]. Cardiac complications during uremia deserve further study to fully elucidate the place of oxidative stress in uremic cardiomyopathy.

The major finding of this study demonstrates that the occurrence of oxidative stress in our model of uremia associated to malnutrition is accompanied with OPN and pro-collagen 
type I expression, two potential profibrotic factors that could be involved in future cardiac remodeling. A longer term experiment is needed to determine the functional consequences of cardiac oxidative stress and second, pathology prevention using NADPH oxidase or tempol should be investigated.

\section{Declaration of interest}

None to declare.

\section{References}

[1] Loos-Ayav C, Briancon S, Frimat L, Andre JL, Kessler M. Incidence of chronic kidney disease in general population, EPIRAN study. Nephrol Ther 2009;5 Suppl 4:S250-5.

[2] Terrier N, Senecal L, Dupuy AM, Jaussent I, Delcourt C, Leray H, Rafaelsen S, Bosc JY, Maurice F, Canaud B and others. Association between novel indices of malnutrition-inflammation complex syndrome and cardiovascular disease in hemodialysis patients. Hemodial Int 2005;9(2):159-68.

[3] Nanayakkara PW, Gaillard CA. Vascular disease and chronic renal failure: new insights. Neth J Med 2010;68(1):5-14.

[4] Kalantar-Zadeh K, Ikizler TA, Block G, Avram MM, Kopple JD. Malnutritioninflammation complex syndrome in dialysis patients: causes and consequences. Am J Kidney Dis 2003;42(5):864-81.

[5] Stenvinkel P, Heimburger O, Lindholm B, Kaysen GA, Bergstrom J. Are there two types of malnutrition in chronic renal failure? Evidence for relationships between malnutrition, inflammation and atherosclerosis (MIA syndrome). Nephrol Dial Transplant 2000;15(7):953-60.

[6] Morena M, Delbosc S, Dupuy AM, Canaud B, Cristol JP. Overproduction of reactive oxygen species in end-stage renal disease patients: a potential component of hemodialysis-associated inflammation. Hemodial Int 2005;9(1):37-46.

[7] Kunz K, Dimitrov Y, Muller S, Chantrel F, Hannedouche T. Uraemic cardiomyopathy. Nephrol Dial Transplant 1998;13 Suppl 4:39-43.

[8] Lopez B, Gonzalez A, Hermida N, Laviades C, Diez J. Myocardial fibrosis in chronic kidney disease: potential benefits of torasemide. Kidney Int Suppl 2008(111):S19-23.

[9] Szalay G, Sauter M, Haberland M, Zuegel U, Steinmeyer A, Kandolf R, Klingel K. Osteopontin: a fibrosis-related marker molecule in cardiac remodeling of enterovirus myocarditis in the susceptible host. Circ Res 2009;104(7):851-9.

[10] Bedard K, Krause KH. The NOX family of ROS-generating NADPH oxidases: physiology and pathophysiology. Physiol Rev 2007;87(1):245-313.

[11] Feillet-Coudray C, Sutra T, Fouret G, Ramos J, Wrutniak-Cabello C, Cabello G, Cristol JP, Coudray C. Oxidative stress in rats fed a high-fat high-sucrose diet and preventive effect of polyphenols: Involvement of mitochondrial and $\mathrm{NAD}(\mathrm{P}) \mathrm{H}$ oxidase systems. Free Radic Biol Med 2009;46(5):624-32.

[12] Poli G, Leonarduzzi G, Biasi F, Chiarpotto E. Oxidative stress and cell signalling. Curr Med Chem 2004;11(9):1163-82.

[13] Cave A, Grieve D, Johar S, Zhang M, Shah AM. NADPH oxidase-derived reactive oxygen species in cardiac pathophysiology. Philos Trans R Soc Lond B Biol Sci 2005;360(1464):2327-34.

[14] Stenvinkel P, Carrero JJ, Axelsson J, Lindholm B, Heimburger O, Massy Z. Emerging biomarkers for evaluating cardiovascular risk in the chronic kidney disease patient: 
how do new pieces fit into the uremic puzzle? Clin J Am Soc Nephrol 2008;3(2):50521.

[15] Price PA, Roublick AM, Williamson MK. Artery calcification in uremic rats is increased by a low protein diet and prevented by treatment with ibandronate. Kidney Int 2006;70(9):1577-83.

[16] Stockelman MG, Lorenz JN, Smith FN, Boivin GP, Sahota A, Tischfield JA, Stambrook PJ. Chronic renal failure in a mouse model of human adenine phosphoribosyltransferase deficiency. Am J Physiol 1998;275(1 Pt 2):F154-63.

[17] Sreejith P, Narasimhan KL, Sakhuja V. 2, 8 Dihydroxyadenine urolithiasis: A case report and review of literature. Indian J Nephrol 2009;19(1):34-6.

[18] Yokozawa T, Zheng PD, Oura H. Experimental renal failure rats induced by adenine Evaluation of free amino acid, ammonia nitrogen and guanidino compound levels. Agric. Biol. Chem 1983;47(10):2341-2348.

[19] Lowry OH, Rosebrough NJ, Farr AL, Randall RJ. Protein measurement with the Folin phenol reagent. J Biol Chem 1951;193(1):265-75.

[20] Yagi K. Assay for blood plasma or serum. Methods Enzymol 1984;105:328-31.

[21] Sunderman FW, Jr., Marzouk A, Hopfer SM, Zaharia O, Reid MC. Increased lipid peroxidation in tissues of nickel chloride-treated rats. Ann Clin Lab Sci $1985 ; 15(3): 229-36$.

[22] Marklund S. Spectrophotometric study of spontaneous disproportionation of superoxide anion radical and sensitive direct assay for superoxide dismutase. J Biol Chem 1976;251(23):7504-7.

[23] Beers RF, Jr., Sizer IW. A spectrophotometric method for measuring the breakdown of hydrogen peroxide by catalase. J Biol Chem 1952;195(1):133-40.

[24] Flohe L, Gunzler WA. Assays of glutathione peroxidase. Methods Enzymol 1984;105:114-21.

[25] Janssen AJ, Trijbels FJ, Sengers RC, Smeitink JA, van den Heuvel LP, Wintjes LT, Stoltenborg-Hogenkamp BJ, Rodenburg RJ. Spectrophotometric assay for complex I of the respiratory chain in tissue samples and cultured fibroblasts. Clin Chem 2007;53(4):729-34.

[26] Rustin P, Chretien D, Bourgeron T, Gerard B, Rotig A, Saudubray JM, Munnich A. Biochemical and molecular investigations in respiratory chain deficiencies. Clin Chim Acta 1994;228(1):35-51.

[27] Wharton DC, Tzagoloff A. Cytochrome oxidase from beef heart mitochondria. Methods Enzymol 1967;10:245-250.

[28] Srere P. Citrate synthase. Methods Enzymol 1969;13:3-11.

[29] Sutra T, Oiry C, Azay-Milhau J, Youl E, Magous R, Teissedre PL, Cristol JP, Cros G. Preventive effects of nutritional doses of polyphenolic molecules on cardiac fibrosis associated with metabolic syndrome: involvement of osteopontin and oxidative stress. J Agric Food Chem 2008;56(24):11683-7.

[30] Sahn DJ, DeMaria A, Kisslo J, Weyman A. Recommendations regarding quantitation in M-mode echocardiography: results of a survey of echocardiographic measurements. Circulation 1978;58(6):1072-83.

[31] de Simone G, Wallerson DC, Volpe M, Devereux RB. Echocardiographic measurement of left ventricular mass and volume in normotensive and hypertensive rats. Necropsy validation. Am J Hypertens 1990;3(9):688-96.

[32] Devereux RB. Detection of left ventricular hypertrophy by M-mode echocardiography. Anatomic validation, standardization, and comparison to other methods. Hypertension 1987;9(2 Pt 2):II19-26. 
[33] Slama M, Susic D, Varagic J, Ahn J, Frohlich ED. Echocardiographic measurement of cardiac output in rats. Am J Physiol Heart Circ Physiol 2003;284(2):H691-7.

[34] Boaz M, Matas Z, Biro A, Katzir Z, Green M, Fainaru M, Smetana S. Serum malondialdehyde and prevalent cardiovascular disease in hemodialysis. Kidney Int 1999;56(3):1078-83.

[35] Husain K, Ferder L, Mizobuchi M, Finch J, Slatopolsky E. Combination therapy with paricalcitol and enalapril ameliorates cardiac oxidative injury in uremic rats. Am $\mathbf{J}$ Nephrol 2009;29(5):465-72.

[36] Chaudiere J, Ferrari-Iliou R. Intracellular antioxidants: from chemical to biochemical mechanisms. Food Chem Toxicol 1999;37(9-10):949-62.

[37] Singh M, Foster CR, Dalal S, Singh K. Osteopontin: Role in extracellular matrix deposition and myocardial remodeling post-MI. J Mol Cell Cardiol 2010;48(3):53843.

[38] Bendall JK, Cave AC, Heymes C, Gall N, Shah AM. Pivotal role of a gp91(phox)containing NADPH oxidase in angiotensin II-induced cardiac hypertrophy in mice. Circulation 2002;105(3):293-6.

[39] Okamoto H. Osteopontin and cardiovascular system. Mol Cell Biochem 2007;300(12):1-7.

[40] Schellings MW, Pinto YM, Heymans S. Matricellular proteins in the heart: possible role during stress and remodeling. Cardiovasc Res 2004;64(1):24-31.

[41] McCurdy S, Baicu CF, Heymans S, Bradshaw AD. Cardiac extracellular matrix remodeling: fibrillar collagens and Secreted Protein Acidic and Rich in Cysteine (SPARC). J Mol Cell Cardiol 2010;48(3):544-9.

[42] Sahai A, Malladi P, Melin-Aldana H, Green RM, Whitington PF. Upregulation of osteopontin expression is involved in the development of nonalcoholic steatohepatitis in a dietary murine model. Am J Physiol Gastrointest Liver Physiol 2004;287(1):G264-73.

[43] Delbosc S, Cristol JP, Descomps B, Mimran A, Jover B. Simvastatin prevents angiotensin II-induced cardiac alteration and oxidative stress. Hypertension 2002;40(2):142-7.

[44] Rugale C, Delbosc S, Mimran A, Jover B. Simvastatin reverses target organ damage and oxidative stress in Angiotensin II hypertension: comparison with apocynin, tempol, and hydralazine. J Cardiovasc Pharmacol 2007;50(3):293-8.

[45] Amann K, Tornig J, Buzello M, Kuhlmann A, Gross ML, Adamczak M, Ritz E. Effect of antioxidant therapy with dl-alpha-tocopherol on cardiovascular structure in experimental renal failure. Kidney Int 2002;62(3):877-84. 


\section{Tables}

Table I: Evidence of uraemia and metabolic disorder at sacrifice time

\begin{tabular}{|lll|}
\hline Plasma measurement & Control diet $(\mathrm{n}=4)$ & Adenine diet $(\mathrm{n}=4)$ \\
\hline Urea $\left(\mathrm{mmol} \mathrm{L}^{-1}\right)$ & $4.78 \pm 0.63$ & $64.85 \pm 14.02^{\mathrm{a}}$ \\
Creatinine $\left(\mu \mathrm{mol} \mathrm{L}{ }^{-1}\right)$ & $39.5 \pm 8.2$ & $602.8 \pm 132.9^{\mathrm{a}}$ \\
Corrected calcium $\left(\mathrm{mmol} \mathrm{L}^{-1}\right)$ & $2.88 \pm 0.04$ & $2.92 \pm 0.03$ \\
Phosphorus $\left(\mathrm{mmol} \mathrm{L}^{-1}\right)$ & $2.39 \pm 0.09$ & $6.74 \pm 0.83^{\mathrm{a}}$ \\
Albumin $\left(\mathrm{g} \mathrm{L}^{-1}\right)$ & $26.3 \pm 0.6$ & $23.0 \pm 0.7^{\mathrm{a}}$ \\
Lipids & & \\
TC $\left(\mathrm{mmol} \mathrm{L}^{-1}\right)$ & $1.68 \pm 0.08$ & $2.69 \pm 0.20^{\mathrm{a}}$ \\
$\mathrm{HDL}-\mathrm{c}\left(\mathrm{mmol} \mathrm{L}^{-1}\right)$ & $0.588 \pm 0.042$ & $0.693 \pm 0.054$ \\
Triglycerides $\left(\mathrm{mmol} \mathrm{L}^{-1}\right)$ & $0.663 \pm 0.131$ & $0.745 \pm 0.137$ \\
$n-H D L-c\left(\mathrm{mmol} \mathrm{L}^{-1}\right)$ & $1.10 \pm 0.04$ & $2.00 \pm 0.17^{\mathrm{a}}$ \\
\hline
\end{tabular}

HDL-c: High-Density Lipoprotein Cholesterol; n-HDL-c: non HDL Cholesterol; TC: Total Cholesterol. Values are mean \pm S.E.M. $(n=4) .{ }^{a}$ Mann-Whitney test significantly different from control at $\mathrm{p}<0.05$.

Table II: Urinary phosphorus and creatinine excretion evolution during the time course of the experiment

\begin{tabular}{|llll|}
\hline \multicolumn{2}{|l}{ Urinary parameters } & Control diet $(\mathrm{n}=4)$ & Adenine diet $(\mathrm{n}=4)$ \\
\hline \multirow{2}{*}{$\begin{array}{l}\text { Creatinine } \\
(\mathrm{mmol} \mathrm{24h}\end{array}$} & Day 3 & $0.104 \pm 0.022$ & $0.126 \pm 0.005$ \\
& Day 14 & $0.141 \pm 0.001$ & $0.078 \pm 0.010^{\mathrm{a}}$ \\
& Day 28 & $0.121 \pm 0.012$ & $0.042 \pm 0.004^{\mathrm{a}}$ \\
\hline \multirow{2}{*}{$\begin{array}{l}\text { Phosphorus } \\
(\mathrm{mmol} \mathrm{24h}\end{array}$} & Day 3 & $0.142 \pm 0.049$ & $0.518 \pm 0.026^{\mathrm{a}}$ \\
& Day 14 & $0.089 \pm 0.039$ & $0.282 \pm 0.009^{\mathrm{a}}$ \\
& Day 28 & $0.084 \pm 0.031$ & $0.152 \pm 0.011$ \\
\hline
\end{tabular}

Values are mean \pm S.E.M. $(n=4) .{ }^{a}$ Mann-Whitney test significantly different from control at $\mathrm{p}<0.05$. 
Table III: Oxidative stress parameters

\begin{tabular}{|c|c|c|}
\hline & Control diet $(n=4)$ & Adenine diet $(n=4)$ \\
\hline \multicolumn{3}{|c|}{ Plasmatic oxidative stress parameters } \\
\hline TBARS $\left(\mu \mathrm{mol} \mathrm{L}^{-1}\right)$ & $1.79 \pm 0.11$ & $2.79 \pm 0.06^{\mathrm{a}}$ \\
\hline \multicolumn{3}{|l|}{ Cardiac oxidative stress parameters } \\
\hline \multicolumn{3}{|l|}{ Oxidative stress markers } \\
\hline TBARS (nmol x mg-1 protein) & $0.563 \pm 0.047$ & $0.687 \pm 0.050$ \\
\hline \multicolumn{3}{|l|}{ Cardiac anti-oxidative enzymes } \\
\hline $\mathrm{SOD}\left(\mathrm{U} \mathrm{x} \mathrm{mg}^{-1}\right.$ protein $)$ & $15.0 \pm 0.6$ & $15.2 \pm 0.7$ \\
\hline Mn-SOD (U x mg ${ }^{-1}$ protein) & $4.07 \pm 0.48$ & $2.88 \pm 0.09^{\mathrm{a}}$ \\
\hline Catalase $\left(\mathrm{U} \mathrm{x} \mathrm{mg}^{-1}\right.$ protein $)$ & $26.3 \pm 1.4$ & $46.2 \pm 1.8^{\mathrm{a}}$ \\
\hline GPx (mU x mg ${ }^{-1}$ protein $)$ & $2176 \pm 86$ & $3002 \pm 121^{\mathrm{a}}$ \\
\hline \multicolumn{3}{|l|}{ NADPH oxidase activity } \\
\hline superoxide anion (RLU x mg-1 protein) & $608 \pm 50$ & $1823 \pm 318^{a}$ \\
\hline \multicolumn{3}{|l|}{ Mitochondrial activity } \\
\hline $\mathrm{CS}\left(\mathrm{mU} \times \mathrm{mg}^{-1}\right.$ protein) & $2696 \pm 124$ & $2680 \pm 82$ \\
\hline $\mathrm{CI}$ (mU x mg-1 protein) & $541 \pm 32$ & $507 \pm 34$ \\
\hline CII (mU x mg-1 protein) & $1108 \pm 23$ & $1016 \pm 67$ \\
\hline $\mathrm{CII}+\mathrm{III}\left(\mathrm{mU} \times \mathrm{mg}^{-1}\right.$ protein $)$ & $420 \pm 73$ & $324 \pm 7$ \\
\hline $\mathrm{COX}\left(\mathrm{mU} \times \mathrm{mg}^{-1}\right.$ protein $)$ & $187 \pm 30$ & $151 \pm 12$ \\
\hline
\end{tabular}

TBARS: thiobarbituric acid-reactive substances; SOD: superoxide dismutase; Mn-SOD: manganese-SOD; GPx: glutathione peroxidase; RLU: relative light units; CS: citrate synthase; CI: complex I; CII: complex II; CII+III: complex II+III; COX: cytochrome c oxidase. Values are mean \pm S.E.M. $(n=4) .{ }^{a}$ Mann-Whitney test significantly different from control at $\mathrm{p}<0.05$. 
Figure captions
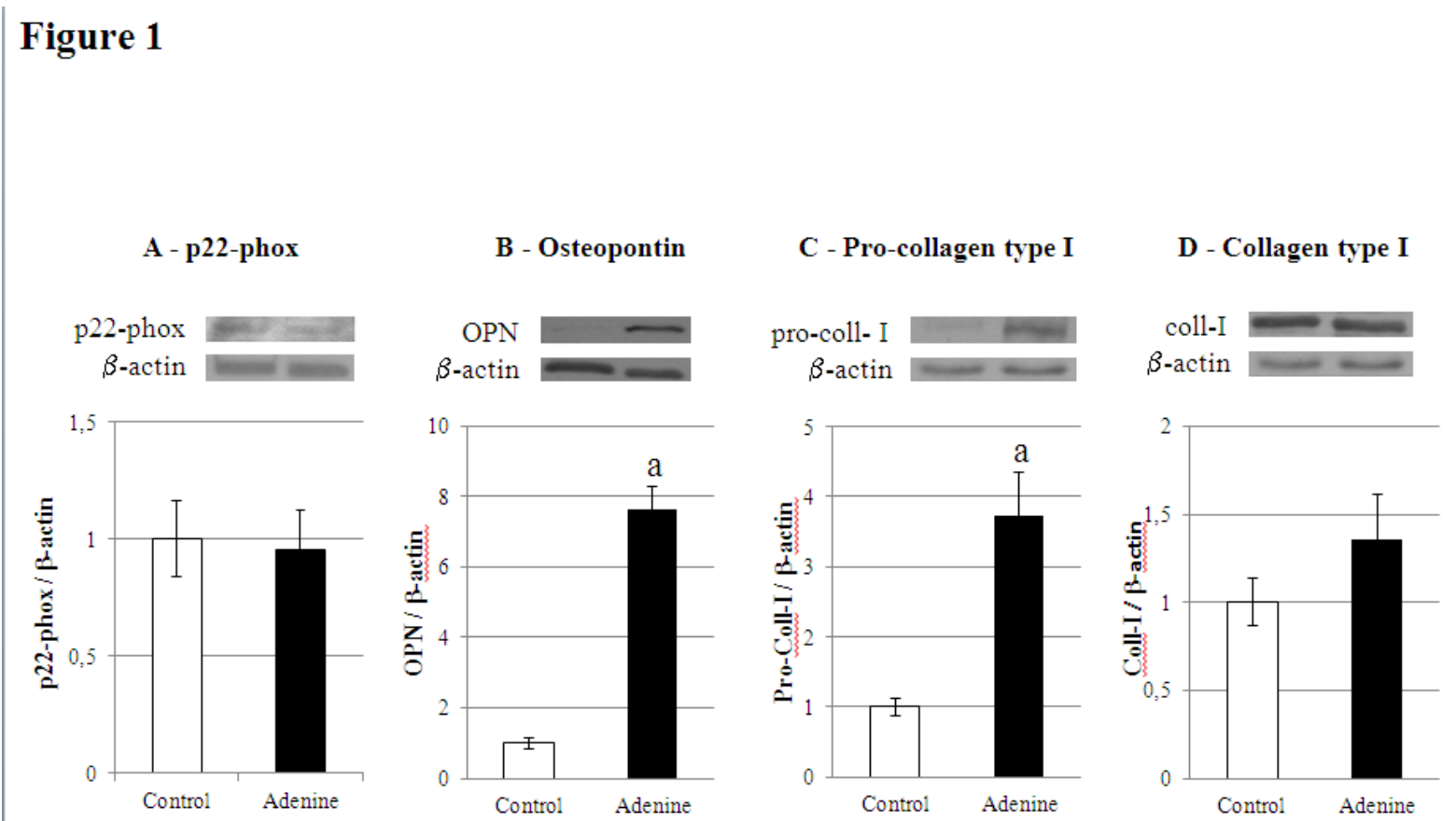

Figure 1: Expression of cardiac proteins in left ventricle: p22-phox (A), osteopontin (B), pro-collagen type I (C) and collagen type I (D). OPN: osteopontin, coll-I: collagen type I, pro-coll-I: pro-collagen type I. Values are mean \pm S.E.M. $(n=4) .{ }^{a}$ Mann-Whitney test significantly different from control at $\mathrm{p}<0.05$.

\section{Figure 2}

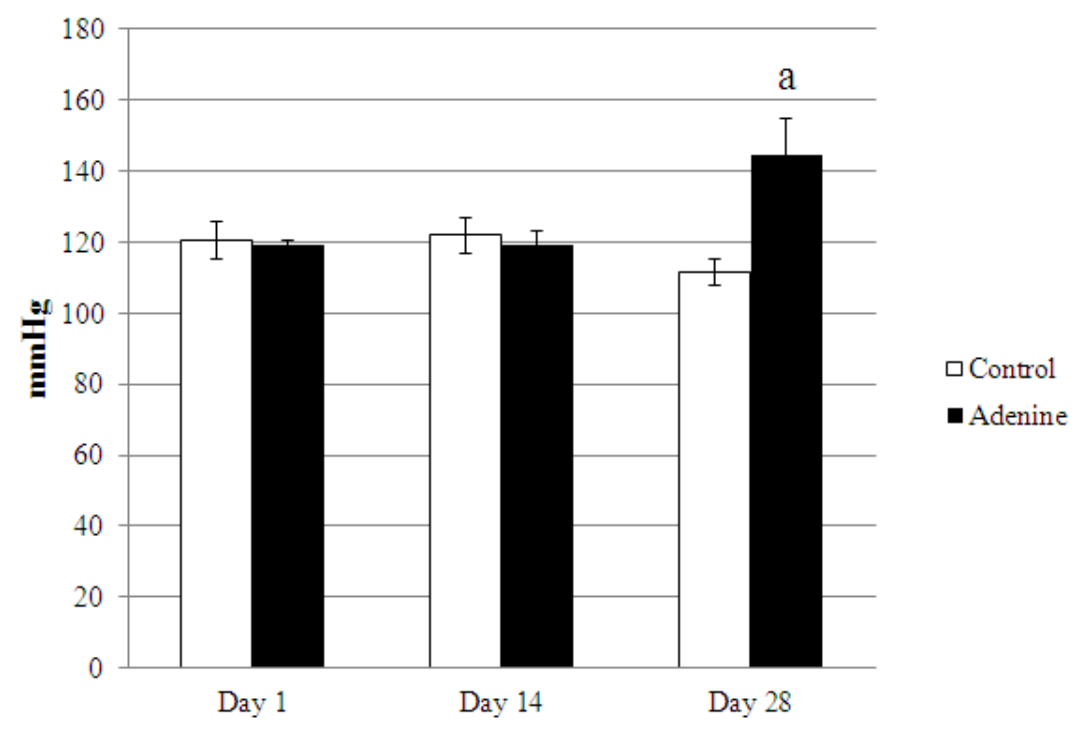

Figure 2: Tail-cuff blood pressure follow-up. Values are mean \pm S.E.M. $(n=4) .{ }^{a}$ MannWhitney test significantly different from control at $\mathrm{p}<0.05$. 